\title{
Navigating Strategies in Teaching Science in the New Normal: Input to Pre-Service Teachers
}

\author{
Maria Lourdes G. Tan, EdD \\ marialourdestan71@gmail.com \\ Leyte Normal University, Paterno St., Tacloban City 6500, Leyte, Philippines
}

\begin{abstract}
Teachers face new challenges and perspectives with the new teaching modality. This study aimed to identify science teachers' difficulties, coping mechanisms and suggested teaching strategies using online learning modalities in the new normal. The study participants were ten (10) in-service public Junior High school science teachers who were purposely selected. Data were collected through a semi-structured questionnaire in the google form, and virtual focused group discussion using Colaizzi's method of data analysis. Results revealed the following difficulties: unstable internet connection and hands-on activities and experiments. Coping mechanisms include technology resource enhancement preparing pre-recorded discussion and activities. In addition, in-service teachers suggested using interactive science games and innovative approaches in teaching science.
\end{abstract}

Keywords : pre-service teachers, interactive science strategies, learning difficulties, online learning, new normal

\section{Introduction}

Science teaching undergoes seamless transition for both teachers and students during this time of the COVID-19 pandemic. The continuous rising of pandemic patients affects all education sectors in the world (UNESCO, 2020). In the Philippines, the Department of Education implemented the Basic Education Learning Continuity Plan (BE-LCP), which adapted multiple learning modalities such as online learning, modular learning, and blended learning (Deped,2020). Online teaching poses advantages; as mentioned in the study of Means et al. (2013), online learning improves student success and satisfaction. However, it also poses a challenge to science teachers, especially in learning activities. As Liu et al. (2016) mentioned, teaching online requires different methods and strategies compared to the traditional classroom. This conveys the importance of teachers adapting and developing online teaching skills in both online and modular modalities and emphasizing the making of learning materials effective and engaging to students. Studies were conducted and revealed the importance, opportunities, challenges, and guidelines in dealing with online learning challenges during the pandemic (Shivangi,2020). On this premise, the researcher conducted the study to know the difficulties, coping mechanisms and suggested in-service teachers' science teaching strategies.

This research could help teachers in the field choose strategies for effective lesson delivery amidst pandemic.

\subsection{Theoretical Framework}

This research study is anchored on the theory of Outcomes- Based Teaching and Learning (BTL), which focuses on student-centered approaches rather than teacher-centered approaches in educational programs 
delivery (Garret, 2008; Llanes, 2010). This is further supported by the idea of Biggs and Tang (2011), who describe OBTL as constructive alignment because students can construct meaning out of the relevant online activities they are exposed to.

Moreover, the theory of Piaget's Constructivism also supports online learning through the spiral progression of the $\mathrm{K}$ to 12 curriculum where current in-service teachers choose what teaching strategies to use for students to have meaningful learning experiences (Bada, 2015).

Further, the study also considers Gardner's Multiple Intelligences Theory. Through online learning, diverse bits of intelligence of students and individual differences and characteristics were looked up to. It emphasizes what the learner can bring inside the classroom by providing appropriate strategies to promote learning (Bordei, 2016).

\subsection{Review of Literature}

Science teaching is a very challenging task. Teachers are challenged to employ better strategies to make learning enjoyable, though difficult at this pandemic. However, the COVID-19 forced science teachers to become more creative, resourceful, and innovative, focusing on using student-centered techniques and approaches (Barraket, 2005).

Few studies suggested how to teach science using the online modality. However, as cited in the study of Hassard \& Dias (2013), differentiated instructional strategies help students learn by applying technological developments to enhance learning.

Concerning this, Chapay (2020) raised some concerns about the assessment of learning for educators, especially in this time of pandemic that there is no face-to-face class. In another study by Dela Rama et al. (2020), teacher training is essential to enhance awareness and usage of e-learning platforms to facilitate effective learning. Offline approaches can also be applied on areas that do not have internet access. Educators can combine two approaches to consider what is essential in achieving learning objectives (Mertayasa \& Indraningsih, 2020).

As revealed in the study conducted by Shivangi (2020), teachers play a significant role in the success of fully online virtual schooling. Moore (2016) mentioned that teachers' ability to work on real research problems significantly increased student interest in the lesson. Another study confirmed that teaching science with technology increased students' interest in learning and improved students' achievement and engagement (Nawzad \& Said,2018). Students positively reported the effectiveness of online learning during the pandemic, wherein covid cases are not stable. Findings revealed that educational technology is appropriate in teaching and learning (Yildiz, 2020).

In addition, some students reported that they preferred watching video lectures and more active approaches to learning (Leo \& Puzio, 2016).

\subsection{Research Questions}

Specifically, this study seeks to answer the following questions:

1. What difficulties in-service teachers encounter in teaching science using online learning modality?

2. What are the coping mechanisms of in-service teachers with the difficulties encountered in teaching science using online learning modality?

3. What are the suggested strategies of in-service teachers in teaching science using online learning modality? 


\section{Methodology}

\subsection{Research Design}

The study used the descriptive phenomenological method to explore in-service teachers' difficulties, coping mechanisms, and suggestions in responding to the problems in teaching science using online learning modalities.

\subsection{Research Setting}

The study was conducted in one of the leading education universities located in Tacloban City, Leyte, Philippines. The researcher purposely confined the study to the said school, being the frontline teacher training institution in the region and one of the highly recommended universities nationwide. The schools' programs and policies adhered to the university's vision and mission.

\subsection{Research Participants}

The research participants were the Basic Junior High School teachers teaching science subjects for the First Semester of SY 2020-2021. Participants were chosen through purposive sampling. It involves identifying and selecting a group of knowledgeable individuals who share a common field of interest since they are both secondary science majors (Creswell \& Plano Clark, 2011). Utmost confidentiality of the information shared and audio recordings were observed throughout the study. Names of the participants were substituted with pseudo names in the transcript.

\subsection{Research Instrument and Data Collection}

The instrument utilized for the study was a survey questionnaire through google Forms validated by experts. The survey questionnaire was composed of open-ended questions on the difficulties encountered, coping mechanisms, and suggestions to improve teaching science in the online modality of learning. It also includes recording virtual focus group discussions to get deeper information of participants' lives in the conduct of online learning. The results remain anonymous, save time, and can be presented in a paper format, and there is little risk of prejudice (Kothari, 2004). After the online survey, the researchers were guided common-sense rules on disengagement by Lofland's (1990), which include: 1) Avoiding leaving abruptly; 2) Saying goodbye personally; 3) Promising to keep in touch, and 4) Keeping in touch as a situation dictated (De La Cruz, 2020). Researchers also conducted the validity check by having a follow-up online interview with the participants' convenient date and time.

\subsection{Data Analysis}

This study employed Collaizi's Descriptive Phenomenological Method of data analysis, Shosha (2012). The researcher conducted the following: 1) transcribed the data which described the difficulties, coping strategies, and suggested solutions of in-service teachers in teaching science online; 2) get significant statements from the transcriptions; 3) formulated meaning for these meaningful statements, 4) classified the developed meaning and clusters of themes, 5) integrated findings of the study into a detailed description, 6) described the phenomenon of the study, and 7) validated findings with the experiences of participants in online learning. 


\section{Findings and Discussion}

Researchers created some themes to recognize teachers' difficulties, coping strategies, and suggestions in online learning modalities. Based on their interpretations, the following themes were identified:

\subsection{In-service Teachers Difficulties' Encountered in Teaching Science Using Online Learning}

Challenges encountered by teachers in teaching science have a tremendous effect on learning. This taught us to plan alternative online and offline strategies in oder to cater the needs of students. Educational institutions must build resilience in their system to ensure and prioritize these skills in their students (Dhawan, 2020).

Theme 1. Unstable internet connection

Significant Statement 1. "In the middle of my discussion, my power presentation stopped due to low internet connection."

Significant Statement 2. "I once call my student to explain my discussion, then my student suddenly got lost connection."

Theme 2. Conduct of hands-on activities and experiments

Significant Statement 1. "We cannot conduct the activity and experiments online effectively."

Significant Statement 2. "There are topics that will be appreciated more by students if done in a real laboratory set-up."

\subsection{Coping Mechanism of Science Teachers in Online Learning}

Despite the limitations and challenges of the COVID-19 pandemic, education continued, and teachers faced it with positivity, discovered new things, and explored ways to teach science online. Teachers used online instructional materials to make science learning exciting and enjoyable. This enable the teachers to be flexible and deliver lesson online with less difficulty and disruption (Dziuban et al., 2018).

Theme 1. Technology Resource Enhancement

Significant Statement 1. "I attended webinars on how to conduct online teaching, before the start of online classes."

Significant Statement 2. "I practiced and asked help from my colleagues in navigating different online teaching platform."

Theme 2. Giving Clear Instruction and Schedule of Task to Students

Significant Statement 1. "I usually send messages in the class group chat the tasks and schedule of submission."

Significant Statement 2. "Students are informed the dates of submission and even extended the deadlines."

Theme 3. Preparing Pre-Recorded Discussion

Significant Statement 1. "I prepared pre-recorded discussion especially if the weather is not good, and send it to those who were not able to attend the class."

Significant Statement 2. "I record myself doing the activity especially if the activity is a bit difficult or dangerous for the students to do without the guidance of the teacher." 


\subsection{Suggested strategies of teachers teaching science using online learning}

Synchronous online learning also provides opportunities for science teachers to think and rethink how to make learning engaging and practical. Teachers' initiative and adaptive resilience play an excellent role in teaching despite the pandemic. It also points out the adjustment to shortages of digital technology resources and makes use of what is doable (Rwodzi, 2018).

Theme 1. Use of inter-active science games in teaching

Significant Statement 1. "I let them do vlogging using the concepts in science that we had discussed.

Significant Statement 2. "I provide inter-active games in science via online. I am happy because more students participated."

Theme 2. Use of innovative approach in teaching science

Significant Statement 1. "I let my students construct their own understanding of the lesson through making schema and graphic organizer."

Significant Statement 2. "Students are interested to discover new things like constructing models, science do it yourself activities related to the topic using common materials in their surroundings."

\section{Conclusion}

Science teachers faced the daily challenges of online learning modality during the COVID 19 Pandemic. However, teachers look at the positive side of the situation despite the difficulties, specifically in terms of technological aspect, teaching and learning approaches. Furthermore, they find alternatives and translate difficulties encountered into strategies responsive to students' needs and varied learning styles.

\section{Recommendation}

Teachers' struggles can be lightened with the help and support of each one in the school community. This point out the continued support and training on upscaling teachers' technological skills, strategies and use of learning materials needed for virtual learning. It is further suggested to use interactive science games, innovative teaching approaches, technology-based materials, and needs-based curriculum for an effective teaching-learning process.

\section{References}

Bal-Taştan, S., Davoudi, S. M. M., Masalimova, A. R., Bersanov, A. S., Kurbanov, R. A., Boiarchuk, A. V., \& Pavlushin, A. A. (2018). The impacts of teacher's efficacy and motivation on student's academic achievement in science education among secondary and high school students. Eurasia Journal of Mathematics, Science and Technology Education 14(6), 2353-2366.

Barraket, J. (2005). Teaching research method using a student-centred approach?. Critical reflections on practice. Journal of University Teaching \& Learning Practice 2(2) 65-74.

Cahapay, M. B. (2020). Rethinking education in the new normal post Covid-19 era: A curriculum studies perspective. Aquademia 4(2).

Contant, T. L., Tweed, A. L., Bass, J. E., \& Carin, A. A. (2018). Teaching inquiry through inquiry-based instruction. New York, NY: Pear

Danaia, L., Fitzgerald, M., \& McKinnon, D. (2013). Students' perceptions of high school science: What has changed over the last decade?. Research in Science Education 43(4), 1501-1515.

Department of Education. (2016). K to 12 Curriculum Guide Science (Grade 3 to Grade 10). https://www.deped.gov.ph/wpcontent/uploads/2019/01/Science-CG_withtagged-sci-equipment_revised.pdf

Department of Education. (2020). Guidelines on the use of the most essential learning competencies (MELCs). 
https://commons.deped.gov.ph/MELCS-Guidelines.pdf.

Dhawan, S. (2020). Online learning: A Panacea in the time of Covid-19 Crisis. Journal of Educational Technology Systems 49(1), 5-22.

De la Rama, J., Sabasales, M., Antonio, A., Ricohermoso, C., Torres, J., Devanadera, A., \& Alieto, E. (2020). Virtual teaching as the 'new norm': Analyzing science teachers' attitude toward online teaching, technological competence and access. International Journal of Advanced Science and Technology 29(7), 12705-1271.

Hassard, J., \& Dias, M. (2013). The art of teaching science: Inquiry and innovation in middle school and high school. Routledge.

Moore, M. G. (2016). Teaching science online: practical guidance for effective instruction and lab work. Stylus Publishing, LLC.

Nawzad, L., Rahim, D., \& Said, K. (2018). The effectiveness of technology for improving the teaching of natural science subjects. Indonesian Journal of Curriculum and Educational Technology Studies, 6(1), 15-21.

Suter, L. E. (2014). Visiting science museums during middle and high school: A longitudinal analysis of student performance in science. Science Education 98(5), 815-839.

Yildiz, E.P., Cengel, M., \& Alkan, A. (2020). Current trends in education technologies research worldwide: Meta-analysis of studies between 2015-2020. World Journal of Education. 